\title{
Intraocular pressure changes and postural changes of intraocular pressure in experimentally induced Hansen's disease of rhesus, mangabey, and African green monkeys
}

\author{
Naushad Hussein, Bruce Ostler, Bobby J Gormus, Robert Wolf, Gerald P Walsh
}

Francis I Proctor Foundation, University of California, San Francisco, CA 94143, USA

N Hussein

H B Ostler

Delta Regional Primate Research Centre, Covington, Louisiana 70433, USA

B J Gormus

DVM University of Texas, San Antonio, Texas, USA

$R$ Wolf

Leonard Wood Memorial Laboratory for Leprosy

Research, Cebu,

Phillipines

G P Walsh

Correspondence to:

H Bruce Ostler, MD

FI Proctor Foundation,

University of California, San

University of California, San

USA.

Accepted for publication

2 February 1990

\begin{abstract}
In our long term evaluation of patients with Hansen's disease we have frequently found reduction of their intraocular pressure. Furthermore, we noted changes in their intraocular pressure on change of posture. To determine if these changes have any significance we measured the intraocular pressures of 24 experimentally infected and 39 control monkeys in both sitting and reclining positions. We found significant reduction of intraocular pressure in $66.7 \%$ compared with controls in the sitting position, and a significant increase in intraocular pressure in $79 \%$ when checked first in the sitting then in the reclining position. We offer a possible pathophysiological explanation as to why the changes occur.
\end{abstract}

Ocular complications are common in Hansen's disease. Our clinical observations show that in many patients (even younger patients, patients without other evidence of ocular diseases, and patients with disease for only a short period), early ocular involvement probably occurs as shown by decreased intraocular pressure and a significant change in pressure with a change in posture. ${ }^{1}$

To evaluate the significance of intraocular pressure changes we examined the external eyes

Table 1 Experimental group: dose, site, and date of inoculation

\begin{tabular}{llll}
\hline & $\begin{array}{l}\text { M mulatta } \\
\text { (rhesus monkey) }\end{array}$ & $\begin{array}{l}\text { Catys } \\
\text { (mangabey monkey) }\end{array}$ & $\begin{array}{l}\text { Caeithiops } \\
\text { (African green monkey) }\end{array}$ \\
\hline Sex & Male: 8 & Male: 8 & Male: 5 \\
Age (mean) & $2 \cdot 3$ years & 9.9 years & Female: 3 \\
Dose & $2 \cdot 3 \times 10^{7}$ & $1 \cdot 8 \times 10^{5}$ & $6 \cdot 2$ years \\
(range) & $1 \cdot 6 \times 10^{8}$ & $3.3 \times 10^{7}$ & $1 \cdot 1 \times 10^{7}$ \\
Site of inoculation & IV/IC & IV/IC & $8 \cdot 0 \times 10^{10}$ \\
$\begin{array}{c}\text { Date of inoculation } \\
\text { (range) }\end{array}$ & Aug 1986 & Feb 1984 & IV/IC/ID \\
\hline
\end{tabular}

Dose $=$ number of organisms. $\mathrm{IV}=$ intravenous; $\mathrm{ID}=$ intradermal; $\mathrm{IC}=$ intracutaneous.

Table 2 Control group: intraocular pressure observations

\begin{tabular}{|c|c|c|c|c|c|}
\hline \multirow[t]{2}{*}{ Species } & \multirow{2}{*}{$\begin{array}{l}\text { Clinical } \\
\text { Disease }\end{array}$} & \multirow{2}{*}{$\begin{array}{l}\text { Nasal } \\
A F B\end{array}$} & \multirow[t]{2}{*}{$R X$} & $I O P$ Mean $(S D)$ & $m m H g$ \\
\hline & & & & $(S)$ & $(C)$ \\
\hline 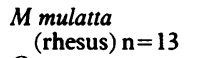 & $0 / 13$ & $0 / 13$ & $0 / 13$ & $\begin{array}{l}15 \cdot 08 / 15 \cdot 08 \\
(1 \cdot 59 / 1 \cdot 73)\end{array}$ & $\begin{array}{c}1 \cdot 08 / 1 \cdot 31 \\
(1 \cdot 38 / 1 \cdot 32)\end{array}$ \\
\hline $\begin{array}{c}C \text { aty } \\
(\text { mangabey) } \\
(\mathrm{n}=13)\end{array}$ & $0 / 13$ & $0 / 13$ & $0 / 13$ & $\begin{array}{l}14 \cdot 54 / 14 \cdot 65 \\
(2 \cdot 56 / 2 \cdot 61)\end{array}$ & $\begin{array}{l}1 \cdot 08 / 1 \cdot 00 \\
(1 \cdot 00 / 0 \cdot 78)\end{array}$ \\
\hline $\begin{array}{l}\text { Caethiops } \\
\text { (African green) } \\
n=3\end{array}$ & $0 / 13$ & $0 / 13$ & $0 / 13$ & $\begin{array}{l}17 \cdot 54 / 18 \cdot 00 \\
(1 \cdot 28 \times 1 \cdot 80)\end{array}$ & $\begin{array}{c}1 \cdot 54 / 1 \cdot 62 \\
(1 \cdot 39 / 1 \cdot 21)\end{array}$ \\
\hline
\end{tabular}

Nasal AFB = nasal scrapings positive for acid fast bacilli. $\mathrm{RX}=$ combination of rifampin with/without dapsone given for clinical disease. IOP Mean $(S)=$ mean sitting intraocular pressure. IOP mean $(C)=$ mean postural change in intraocular pressure. $S D=$ standard deviation. of 24 monkeys (mangabey, rhesus, and African green) which had been inoculated with Mycobacterium leprae organisms. We measured their intraocular pressures in a sitting and reclining position. Many of the animals had developed typical skin and peripheral nerve lesions at the time of the examination. We also examined a group of control monkeys in a similar fashion.

\section{Materials and methods}

We examined both eyes of 24 experimentally infected and 39 control (uninfected) monkeys with a Zeiss hand held slit-lamp, and a Kawo HA-1 hand held applanation tonometer which had been previously calibrated and correlated with a mounted Goldmann applanation tonometer.

The experimentally infected monkeys consisted of eight Macaca mulata (rhesus monkeys), eight Cerocebus atys (sooty mangabey monkeys), and eight Cercopithecus aethiops (African green) monkeys. The control group consisted of 13 mangabey, 13 African green, and 13 rhesus monkeys. The experimentally infected monkeys had been inoculated with $M$. leprae from different sources, at different times and at different sites (Table 1). Control monkeys were unexposed, uninoculated, and housed in separate quarters. Data on each monkey from the time of admission to the Delta Primate Center until the time of our examination were obtained from a log kept on each monkey. The data included time and mode of inoculation (Table 1), observations of each animal (Table 2), results of nasal smears examined for acid fast bacilli (Table 2), and treatment.

The monkeys were examined under neuroleptic anaesthesia obtained by administration of intramuscular ketamine. Following examination with the slit-lamp one drop of $0.4 \%$ benoxinate $\mathrm{HCl}$ and $0.25 \%$ flurorescein $\mathrm{Na}$ was instilled into the inferior fornix of each eye, the excess wiped from the eyelids with clean tissue paper, and the intraocular pressures measured in both the sitting and reclining positions. The monkeys were held by an assistant in the sitting position while the intraocular pressures of each eye were measured and recorded in $\mathrm{mmHg}$ under $(\mathrm{S}=$ sitting). The monkeys were then placed flat on their backs, and the pressure measured in each eye and recorded in $\mathrm{mmHg}$ under ( $\mathrm{L}=$ lying). The postural changes were later calculated and are listed in the tables as $(\mathrm{C}=$ change $)$. Random multiple intraocular pressure readings were measured on selected monkeys of both groups in 
Table 3 Experimental group: intraocular pressure observations

\begin{tabular}{|c|c|c|c|c|c|}
\hline \multirow[t]{2}{*}{ Species } & \multirow{2}{*}{$\begin{array}{l}\text { Clinical } \\
\text { Disease }\end{array}$} & \multirow{2}{*}{$\begin{array}{l}\text { Nasal } \\
A F B\end{array}$} & \multirow[t]{2}{*}{$R X$} & IOP Mean $(S D)$ & $m m H g$ \\
\hline & & & & $(S)$ & $(C)$ \\
\hline$\underset{\text { (rhesus) } n=8}{M \text { mulatta }}$ & $2 / 8$ & $1 / 8$ & $0 / 8$ & $\begin{array}{c}9 \cdot 50 / 10 \cdot 38 \\
(4 \cdot 02 / 3 \cdot 31)\end{array}$ & $\begin{array}{r}5 \cdot 25 / 3 \cdot 87 \\
(3 \cdot 36 / 3 \cdot 44)\end{array}$ \\
\hline $\begin{array}{l}C \text { aty } \\
\text { (mangabey) } \mathrm{n}=8\end{array}$ & $8 / 8$ & $6 / 8$ & $3 / 8$ & $\begin{array}{l}9 \cdot 75 / 9 \cdot 75 \\
(4 \cdot 63 / 6 \cdot 77)\end{array}$ & $\begin{array}{r}5 \cdot 87 / 9 \cdot 00 \\
(4 \cdot 28 / 6 \cdot 76)\end{array}$ \\
\hline $\begin{array}{l}C \text { aethiops } \\
\text { (African green) } \\
\mathrm{n}=8\end{array}$ & $1 / 8$ & $0 / 8$ & $0 / 8$ & $\begin{array}{c}7 \cdot 25 / 6 \cdot 63 \\
(3 \cdot 11 \times 3 \cdot 57)\end{array}$ & $\begin{array}{c}6 \cdot 88 / 8 \cdot 25 \\
(2 \cdot 71 / 2 \cdot 91)\end{array}$ \\
\hline
\end{tabular}

the sitting and reclining positions. The readings were reproducible and the changes immediate and persistent.

\section{Results}

Control group (Table 3). The mean intraocular pressure (IOP) in the 13 mangabey monkeys while sitting was (OD/OS) $14.54 / 14.65 \mathrm{mmHg}$ (SD 2.56/2.61); in the 13 rhesus monkeys the mean intraocular pressure while sitting was $(\mathrm{OD} /$ OS) $15 \cdot 08 / 15.08 \mathrm{mmHg}$ (SD 1.59/1.73); and in the 13 African green monkeys the mean intraocular pressure was (OD/OS) 17.54/18.00 mmHG (SD 1·28/1·80). The mean postural change (lying - sitting $=$ change) in the mangabey monkeys was $1 \cdot 08 / 100 \mathrm{mmHg}$ (SD 1.00/0.78); in the rhesus monkeys the change was $1 \cdot 08 / 1 \cdot 31 \mathrm{mmHg}$ (SD $1 \cdot 38 / 1 \cdot 32$ ) and in the African green monkeys it was $1.54 / 1.62 \mathrm{mmHg}$ (SD 1.39/1.21).

Experimental groups. All three species of inoculated/infected monkeys had a significantly lower sitting intraocular pressure and significant postural changes (elevation of pressure when in the reclining position). Asymmetry of intraocular pressure was also observed in all inoculated monkeys. At the same time we could not detect evidence of external disease. Specifically, we looked for evidence of keratitis, corneal nerve beading, episcleritis, scleritis, iritis, and cataracts. Two monkeys as noted below, however, had conjunctival granulomas.

Rhesus monkeys. Four of the eight monkeys in the rhesus group were inoculated eight months before our examination, the other four nine months before. The mean age was $2 \cdot 3$ years. Clinical lesions at dermal inoculation sites were present in one monkey after four months and one other monkey after eight months. The others were free of clinical disease. In this group of monkeys the mean intraocular pressure $(S)$ was $9.5 / 10.38 \mathrm{mmHg}$ (SD 4.02/3.31), and the mean postural change in intraocular pressure $(C)$ was $5 \cdot 25 / 3 \cdot 87 \mathrm{mmHG}$ (SD 3.36/3.44).

Mangabey monkeys. There were two subgroups of mangabey monkeys. One group had a mean age of $13 \cdot 1$ years and had been inoculated 40 months before our examination. The other group had a mean age of 4.7 years and was inoculated 30 months before. All monkeys in these two groups developed clinical signs of infection after six to 28 months. Four mangabey monkeys had sitting intraocular pressure $(S)$ of $<10 \mathrm{mmHg}$ and seven monkeys had postural change in intraocular pressure (C) of $>5$; furthermore, four monkeys had postural change in intraocular pressure (C) of $>10$ in one or both eyes.

Six mangabey monkeys had positive nasal smears for acid fast organisms. Three of these monkeys had a sitting intraocular pressure $(S)$ of $<10 \mathrm{mmHg}$ and five had postural change in intraocular pressure $(C)$ of $>5$. In this group the mean sitting intraocular pressure (S) was $\mathbf{9 . 7 5}$ / $9.75 \mathrm{mmHg}$ (SD $4 \cdot 63 / 6 \cdot 77$ ), and the mean postural change in intraocular pressure (C) was 5.87/9.00 mmHg (SD 4·28/6.76).

Two mangabey monkeys had conjunctival granulomas (biopsy-positive for acid fast bacilli); all others had eyes of normal appearance.

African green monkeys. The African green monkeys were inoculated between five and 73 months before our examination. One monkey had developed clinical findings 43 months after inoculation. In seven monkeys the intraocular pressure $(S)$ was $<10$ and the intraocular pressure (C) was $>5$ in one or both eyes. In the African green monkeys the mean intraocular pressure (S) was $7 \cdot 25 / 6 \cdot 63 \mathrm{mmHg}$ (SD 3.11/3.57), and the mean intraocular pressure $(C)$ was $6 \cdot 88 / 8 \cdot 25$ $\mathrm{mmHg}(\mathrm{SD} 2 \cdot 71 / 2 \cdot 91)$. The eyes of all this group appeared normal, and the nasal smears were negative for acid fast organisms.

\section{Discussion}

The discovery of what appears to have been a natural infection with $M$ leprae in a mangabey monkey (A015) several years ago has given us the possibility of studying the natural evolution of ocular lepromatous disease. Finding ourselves limited to the observation of low intraocular pressures in many humans with Hansen's disease and without knowing the duration or mode of infection in these patients, we turned to the nonhuman primate model for further study. ${ }^{23}$

Three species of monkeys have now been studied - rhesus, mangabey, and African green. The mangabey is the most susceptible to infection and develops typical clinical disease. All eight that we evaluated developed typical clinical manifestations of Hansen's disease six to 28 months following inoculation. Of this same group five out of eight had significantly low intraocular pressures (S) and seven out of eight had significant postural changes in intraocular pressures (C) of one or both eyes.

The rhesus monkey is moderately susceptible to $M$ leprae. In the group that we studied two of eight developed clinical signs of Hansen's disease four to eight months after inoculation. Of this same group five of eight had a signficantly low intraocular pressure and significant postural changes in intraocular pressure.

The African green monkey is the most resistant of the three species to $M$ leprae. In the group we studied only one monkey developed clinical manifestations of Hansen's disease, while seven out of eight had significantly low intraocular pressure and significant postural changes in intraocular pressure.

Our data indicate that, regardless of species, susceptibility to the organisms and the development of clinical manifestations of Hansen's disease, there is a significant chance of organismal spread by haematogenous dissemination or by the autonomic nervous system once the subject is inoculated with the organism. Haematogenous spread and/or autonomic spread of the 
organism results in the organism often becoming localised in the ciliary body region, which in turn causes early damage to the autonomic nerve fibres and end organs.

Low intraocular pressure in disease states results from reduced aqueous humour production or increased uveoscleral outflow. Significant postural change in intraocular pressure is thought to be the result of reduction of local adrenergic receptors in the anterior segment. We believe the damage is manifested in our monkeys by reduction of intraocular pressure and loss of homoeostasis in the intraocular pressure on change in posture.

In humans the damage is manifested by reduction of intraocular pressure, loss of homoeostatic mechanisms for intraocular pressure control, loss of accommodation, pinpoint or irregular pupils, a low-grade iritis, and phthisis bulbi. Pathological examinations of human eyes also show damage to the ciliary body and anterior uveal tract, with atrophy and hyalinisation of the ciliary body. ${ }^{4-11}$

The ocular complications in Hansen's disease are limited to the anterior segment of the eye. The ocular adnexa (brows, lids, eyelashes, and nasolacrimal system), conjunctiva, cornea, sclera, iris, and lens are often involved. These structures are probably favoured sites of localisation and multiplication of the leprosy bacillus because of their relatively cool temperature, their rich nerve supply, and the presence of levodopa (a precursor for melanin pigment)..$^{12-14}$

None of the monkeys which we studied have had ocular changes clinically. Repeated examinations of these monkeys, however, will give us a unique opportunity to follow the complex mechanisms of ocular leprosy, and of much interest will be the eventual outcome of the eyes which show decreased intraocular pressures and loss of homoeostatic mechanism of intraocular pressure control.

NH Was supported in part by the E A Baker Foundation, Canadian National Institute for the Blind, Canada; the Aga Khan Foundation, Switzerland; and the Albert and Lotte Haas Foundation, San Francisco.

BJ Gormus was supported in part by grant 2R22AI19302 from the National Institute of Allergy and Infectious Diseases, grant RR= 00164 from the National Institute of health, and by a grant from the Victor Heiser Program for Leprosy Research.

1 Hussein N, Courtright P, Ostler HB, Hetherington J, Gelber RH. Low intraocular pressure and postural changes in intraocular pressure in Hansen's disease patients. Am $\mathcal{J}$
Ophthalmol 1989; 108: $80-3$.

2 Martin LN, Gormus BJ, Wolf RH, Walsh GP, Meyers WM, Binford CH. Experimental leprosy in nonhuman primates. Adv Vet Sci Comp Med 1983; 28: 201-36.

3 Meyers WM, Walsh GP, Brown HL, et al. Leprosy in a mangabey monkey - naturally acquired infection. Int $\mathcal{f}$ Lepr Other Mycobact Dis 1985; 53: 1-14.

4 Greaves D, Perkins ES. Influence of the sympathetic nervous system on the intraocular pressure and vascular circulation of the eye. BrF Ophthalmol 1952; 36: 258-64.

5 Jaffe NS. Sympathetic nervous system on the intraocular pressure. Am f Ophthalmol 1948; 31 : 1597.

6 Slem G. Clinical studies of ocular leprosy. Am $\mathcal{f}$ Ophthalmol 1971; 71: 431-4.

7 Allen JH, Byers JL. The pathology of ocular leprosy. I. Cornea. Arch Ophthalmol 1960; 64: 216-20.

8 Hashizuma $\mathrm{H}$, Shionuma E. Electron microscopic studies of lepromatous changes in the iris. Int $\mathcal{f}$ Lepr Other Mycobact Dis 1965; 33: 61-82.

9 Pattyn SR. Bacteriology of Mycobacterium leprae. Lepr Rev June 1983 (special issue).

10 Holmes WJ. The eyes in leprosy. Trans Ophthalmol Soc UK 1961; 81: 397.

11 Holland MGL, Sallman V, Collins EM. A study of the innervation of the chamber angle. Am $\mathcal{F}$ Ophthalmol 1956; 42: 148-61.

12 Ffytche TJ. Role of iris changes as a cause of blindness in lepromatous leprosy. $\mathrm{Br}$ f Ophthalmol 1981; 65: 231-9.

13 Spaide R, Nattis R, Lipka A, D'Amico R. Ocular findings in leprosy in United States. Am $\mathcal{F}$ Ophthalmol 1985; 100: 411-6. 14 Ffytche TJ. The eye and leprosy. (Editorial.) Lepr Rev 1981; 